\title{
REGIONAL INCOME INEQUALITY IN A DEVELOPED NATION: A CROSS-SECTIONAL STUDY OF AUSTRALIAN SUB-STATE REGIONS
}

\author{
Mark McGillivray and Matthew Peter*
}

\begin{abstract}
This paper focuses on patterns of income inequality among Australian sub-state regions for the census years 1976, 1981, and 1986. Using single-equation econometric techniques, its principal objective is to explain these patterns. Like a number of previous studies, we hypothesize that the level of sub-state regional inequality is a function of the level of regional development. We also consider the importance of a number of other factors to regional income inequality, including: labor market and demographic and geographic characteristics. Our results indicate that these factors do impact the level of Australian sub-state regional inequality of incomes.
\end{abstract}

\section{INTRODUCTION}

Patterns of income inequality have long been of interest at both theoretical and applied levels of research. Much of this interest originated from the pioneering work of Simon Kuznets. Kuznets (1955) proposed what now has become known as the "inverted U" or bell-shaped pattern of income inequality. While essentially describing an intertemporal pattern of personal income inequality at the national level, the Kuznets inverted $U$ has formed the theoretical basis of a number of empirical cross-sectional studies that analyze income inequality at the regional level in developed nations. Regional income inequality is altematively defined as the variation of income among states within a nation, among counties within a state, or among individuals (or families) within a sub-state.

This paper focuses on patterns of income inequality at the sub-state level. It seeks to establish the determinants of income inequality among families in Australian sub-state regions using cross-sectional data for the census years 1976, 1981, and 1986. In addition to the level of development, it is hypothesized that Australian sub-state regional income inequality is a function of a range of factors including labor market and demographic and geographic characteristics of these regions. As a starting point to this analysis, we review existing empirical crosssectional studies of regional income inequality in developed nations with special reference to the Amos $(1986,1988)$ "augmented inverted U" hypothesis and the

\footnotetext{
*Lecturer in Economics, Faculty of Management and Business, Deakin University and Research Fellow, Institute of Applied Economic and Social Research, The University of Melboume. The authors are grateful for the useful comments and suggestions provided by Dr. Tran-Nam Binh, the editors of this journal and three anonymous referees who read an earlier draft on this paper. Any remaining errors or omissions are, of course, the responsibility of the authors.
} 
findings of his research. Amos' interpretation of his findings, which are based on both cross-sectional and small-sample time series data, is questioned.

The paper consists of six sections, including the introduction. Section II discusses more fully the regional inequality-development nexus and the Amos inverted augmented $U$ hypothesis. Section III formulates a model suitable for analyzing Australian cross-regional income inequality. Section IV provides details of the data used to estimate this model and the delineation of Australian sub-state regions. After outlining the estimation procedure, Section $\mathrm{V}$ discusses the econometric results. Concluding remarks are made in Section VI.

\section{PATTERNS OF REGIONAL INCOME INEQUALITY WITH SPECIAL REFERENCE TO THE AMOS AUGMENTED INVERTED U}

Kuznets' inverted U hypothesis suggests that in the early stages of development, the level of income inequality rises, while at high levels of development, income inequality decreases and eventually stabilizes. Williamson (1965) adapted this hypothesis to cross-sectional regional inequality data in his study that analyzed, inter alia, sub-state inequality of per capita income among counties in the United States for census years 1950 and 1960. Williamson's hypothesis was that, as the United States had attained a reasonably high level of development, the income inequality levels of sub-national regions would, at a single point in time, be distributed along the downward sloping section of Kuznets' inverted U. That is, those regions with relatively low levels of development would be expected to have high income inequality levels, whereas those that had attained higher levels of development and had progressed further along the Kuznets cycle would be expected to experience lower levels of income inequality. Williamson provides a number of reasons as to why regional inequality may decrease in the latter stages of development: government policies aimed at equalizing regional growth rates and income inequality levels, the discovery of new resources in less developed regions, and the subsequent migration of labor and capital.

A number of more recent studies have adopted the Williamson approach, including those conducted by Amos $(1986,1988)$. Amos' primary interest is subregional income inequality patterns after the inverted $U$ has been completed or, more generally, after relatively high levels of development have been achieved. Amos (1988) highlights two patterns of the inequality-regional development nexus, each based on the simple neoclassical factor market equilibrium mechanism. Both patterns are replicated in Figure 1. The first pattern is one of stabilization. For stabilization to occur, regional growth rates must equalize and 
relative mean regional incomes must remain unchanged. In such an environment, regions would be scattered along a path approximating $b c$.

In proposing his second pattern, Amos questions whether regional inequality will in fact stabilize during the latter stages of development, as it would be naive to expect regional growth rates to equalize and relative per capita incomes to remain unchanged, given the often dynamic nature of regional growth. In such an environment, Amos proposes a second pattern: the so-called "augmented inverted $U$," where a simple increase-decrease inverted $U$ is replaced by a pattern of increase-decrease-increase. In Figure 1, this pattern is depicted as path abd. At relatively high levels of development, such a pattern dictates that at any particular point in time, regions actually traverse downward and upward sloping sections (that is, to the left and right of point $b$ ) of the augmented U. Those at relatively low levels of development would be scattered along a path approximating $a b$, whereas the more developed regions would be scattered along $b d$. Amos (1986, 1988) tested for an augmented U cycle by fitting a quadratic equation to crosssectional data for the census years 1950 to 1980 , and also time series data covering the period 1969 to 1983 , for sub-states in the United States. ${ }^{1}$ On the basis of these tests, Amos claimed "strong evidence" of such a cycle.

\section{FIGURE 1}

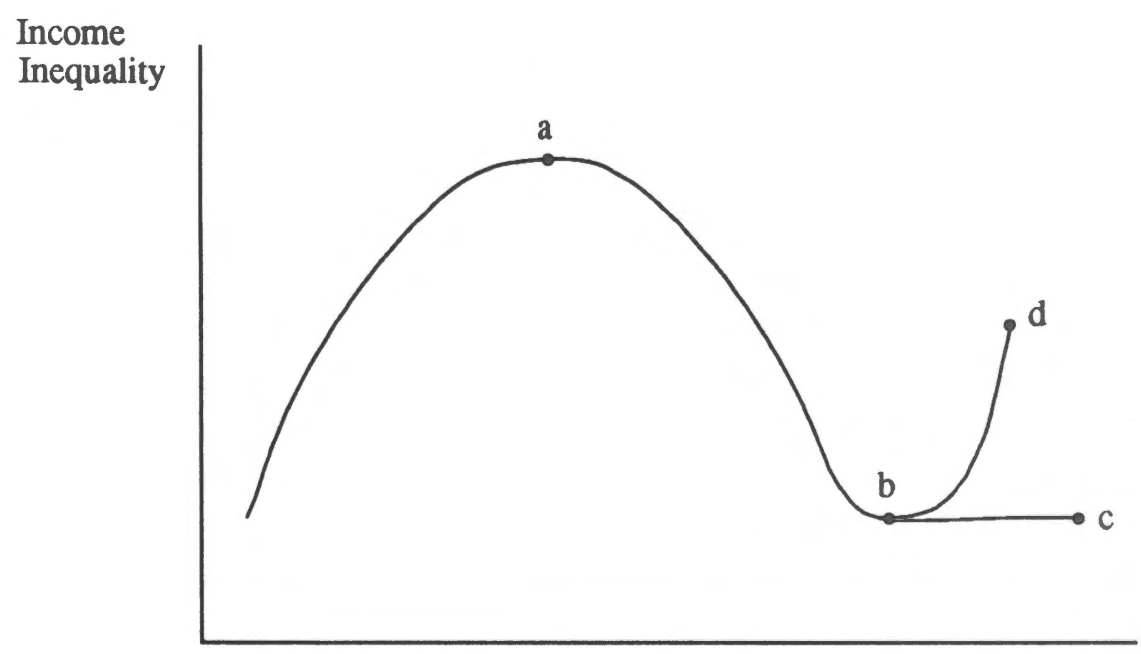

Development 
With respect to Amos' hypothesis, we agree that, in a dynamic environment, it would be most unlikely that regional growth rates equalize and that relative mean incomes would remain constant over time. However, we dispute Amos' interpretation that a quadratic relationship between regional inequality and development, observed from sub-national cross-regional and small-sample time series (i.e., 15 observations) data for a developed nation, is evidence of what is essentially a renewed Kuznets cycle. The reason for this, we believe, is quite clear. Amos $(1988,552)$ postulates that the inverted $U$ cycle has its origins in immense disequilibrating shocks initiated by the industrial revolution of the 1700 s and westward expansion of the 1800 s, which caused income inequality to rise, while the decline in inequality was due to per capita income convergence during the $1900 \mathrm{~s}^{2}$ Within such a time period, Amos asserts that "regional income inequality stabilization indicates the completion of a three-hundred year adjustment" (Amos 1988,552 ).

It is the seemingly long-term nature of this process on which we challenge Amos' interpretation of his findings. If regions were to traverse Amos' augmented inverted $U$, growth rates and differences in relative incomes would have to be of magnitudes that set regions many decades, perhaps centuries, apart in terms of their development levels. While this would seem unlikely in a developed nation, one would also have to confirm that (1) a disequilibrating shock of the magnitude of the industrial revolution has occurred in recent decades, and (2) that even if such a shock did occur, the above-mentioned factors-government policy, migration of labor and capital, and discovery of resources-had not offset the potential impact of the shock on the distribution of regional income.

How then does one interpret Amos' findings, especially those based on cross-sectional data? It would seem more plausible that a quadratic relationship between inequality and development observed from cross-sectional or smallsample time series data for regions in a developed nation is evidence of minor and frequent oscillations around some longer-term trend. It is important to note that we do not unequivocally dismiss the augmented inverted $U$; we simply posit that such a cycle, observed from the previously mentioned data, depicts no more than short-run oscillations. Such cycles, together with Amos' augmented inverted U, are shown in Figure 2. We should also note that while Figure 2 assumes a longerterm trend of stability, this may not necessarily be the case. Based on our preceding remarks (though our suspicion that in developed countries the regional inequality-development nexus now accords to a long-run path of relative stability), our point is that it is an error to draw inferences regarding the nature of the longer trend from cross-sectional and small-sample time series data. 


\section{FIGURE 2}

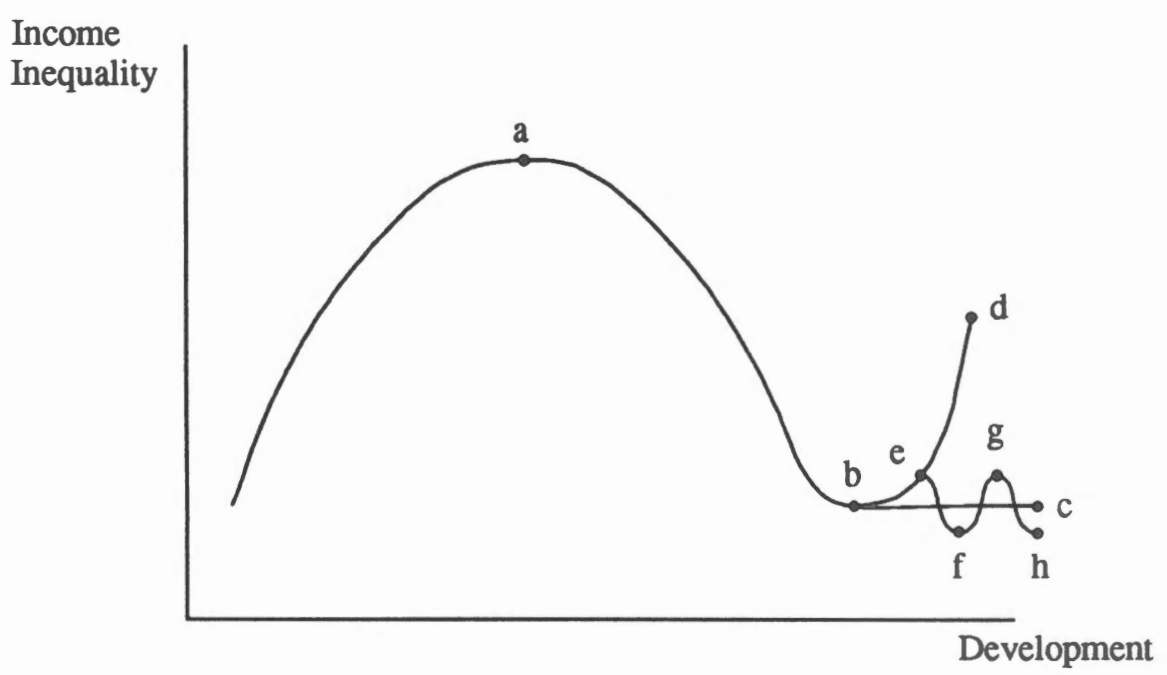

\section{A MODEL OF CROSS-REGIONAL INCOME INEQUALITY}

Against this background, a model of Australian cross-regional (or more specifically, sub-state statistical division) income inequality is formulated. As a starting point, we propose the following quadratic equation:

$$
G_{i}=\alpha+\beta_{1} Y F A M_{i}+\beta_{2} Y F A M_{i}^{2}+\delta_{k} Z_{k i}+\mu_{i}
$$

$G_{\mathrm{i}}$ is the Needleman (1978) version of the Gini coefficient, a well-known and widely used index of income inequality, for the $i$ th region. $Y F A M_{i}$ is the mean family income of this region, $\alpha$ is a constant, $\beta_{1}$ and $\beta_{2}$ are inequality-development parameters, $\mu_{\mathrm{i}}$ is an error term and $\mathrm{i}=1, \ldots, n$. It follows that mean family income serves as an indicator of the level of regional development. $\delta_{\mathrm{k}}$ is a vector of $k$ additional parameters and $Z_{k i}$ is a vector of $k$ additional variables. While we very much expect regional income inequality to be related to the level of regional development, it is unlikely that $Y F A M_{i}$ and $Y F A M_{i}^{2}$ will alone offer a reasonable explanation of the variation in income inequality within regions. ${ }^{3}$ Indeed, one would expect, a priori, that a range of variables have an equal potential to impact upon regional income inequality. 
While one could identify an exhaustive list of additional variables, we limit ours to those pertaining to labor market, demographic, and geographic characteristics of the $i$ th region. The specific variables chosen are given in the following equation:

$$
\begin{aligned}
G_{i}=\alpha & +\beta_{1} Y F A M_{i}+\beta_{2} Y F A M_{i}^{2}+\delta_{1} P R_{i}+\delta_{2} A P_{i}+\delta_{3} S P_{i}+\delta_{4} M P_{i} \\
& +\delta_{5} D_{1 i}+\delta_{6} D_{2 i}+\varepsilon_{i}
\end{aligned}
$$

The first additional variable $\left(P R_{i}\right)$ is the $i$ th region's labor force participation rate. While intuitively one may expect participation rates to be negatively correlated to income inequality levels, we believe that the opposite is more likely to be the case with respect to Australia. In recent decades a principal determinant of variation in participation rates, both at national and sub-national levels, has been the growth of participation rates of married women. When there is an increase in a region of married females entering the labor force (and therefore some proportion into paid employment), the number of families with double incomes in that region also increases, which in turn would lead to greater income inequality. On these grounds, one would expect that regions with high participation rates would have greater levels of income inequality. $\delta_{1}$ is therefore expected to display a positive sign.

The second additional variable $\left(A P_{i}\right)$ is the $i$ th region's percentage of total population aged 65 years and over. Given that this is the normal retirement age in Australia, and that retirees usually are the recipients of relatively low fixed incomes, it is expected that the greater this percentage, the greater would be the degree of income inequality. On these grounds $\delta_{2}$ is expected to be positive.

The third such variable $\left(S P_{i}\right)$ is the $i$ th region's percentage of single-parent families. It is usually the case in Australia that the heads of single-parent families are constrained from entering the work force, and as a consequence are dependent on low and fixed government social security payments. It follows that regions with larger proportions of single-parent families would have larger levels of income inequality. As such, $\delta_{3}$ is expected to be positive.

The fourth additional variable $\left(M P_{i}\right)$ is the percentage of the $i$ th region's population who are recently arrived overseas migrants. We define a recently arrived migrant as one who has taken residence in Australia during the previous five years. For a number of reasons, such as language barriers, relatively poor education levels or racial discrimination, migrants tend to be concentrated in lowpaying jobs. On these grounds, one may at first glance expect $\delta_{4}$ to display a positive sign. However, this ignores the extreme spatial concentration of recently arrived migrants in Australia. The Australian experience has typically been one of 
very high concentration of migrants in specific regions. Given the uniformity of recently arrived migrant incomes, together with regional concentration, one would expect that the greater the proportion of such migrants in any given region, the lower the level of income inequality. $\delta_{4}$ is therefore expected to display a negative sign.

The fifth variable $\left(D_{1 i}\right)$ is a dummy variable taking the value of 1 if the $i$ th region is situated in a remote area, or zero if otherwise. Like Alonso (1968) and Maxwell and Peter (1988) we believe, a priori, that there is good reason to expect that income inequality in remote regions will differ from centrally located regions. For example, it is reasonable to assume that trained management and technical personnel would receive higher incomes simply to attract them to remote regions. By contrast, long-term residents would not be able to command such incomes. On these grounds $\delta_{5}$ is expected to display a positive sign.

The final additional variable $\left(D_{2 i}\right)$ is a second dummy, in this case representing possible rural-urban differences in income inequality. Australia, when compared to most other developed countries, is characterized by a particularly high degree of urbanization and this may exacerbate differences in the distribution of income between rural and nonrural regions. $D_{2 i}$ takes the value of 1 if region $i$ is an agricultural region, or zero if otherwise. $\delta_{6}$ is expected to display a positive sign. ${ }^{4}$

\section{DATA AND DELINEATION OF REGIONS}

Income data for Australian regions first became available with the publication by the Australian Bureau of Statistics (ABS) of the Census of Housing and Population in 1976. Subsequent censuses also provide regional data for the years 1981 and 1986. Correspondingly, all data required to calculate the Needleman Gini $\left(G_{i}\right)$, together with mean family income $\left(Y F A M_{i}\right)$ for the years under consideration, were taken from the published findings of these censuses. The ABS defines families as blood relatives occupying the same dwelling and family income as gross income from all sources of the family head, his or her spouse and dependent children aged 15 to 20 years. ${ }^{5}$ Data required for the calculation of the remaining non-dummy variables contained in equation (2) were also obtained from the findings of the ABS censuses.

In the collection and reporting of the census data, the ABS divides Australia into 58 statistical divisions. With the exception of the two Northern Territory divisions and the area comprising the Australian Capital Territory, ${ }^{6}$ it is these divisions that we treat as sub-state regions. Thus, in equation (2) $n=55$. The breakdown of these divisions by states is as follows: 12 in New South Wales and 
Victoria, 11 in Queensland, 7 in South Australia, 9 in Western Australia, and 4 in Tasmania. These divisions and their Needleman Gini coefficients are listed in Table 1.

\section{ECONOMETRIC PROCEDURE AND RESULTS}

It is well known that econometric models employing grouped data, such as equation (2), are subject to heteroskedasticity of the form $\sigma^{2} / \mathrm{m}_{i}$, where $m_{i}$ is the number of families in the $i$ th region. To ensure the accuracy of results, our model was estimated using the weighted least squares (WLS) method. Given the nature of error term variance, the weight employed is $\sqrt{m_{i}}$. Our estimating equation is therefore given as:

$$
\begin{aligned}
\sqrt{m_{i}} G_{i}= & \alpha \sqrt{m_{i}}+\beta_{1}\left(\sqrt{m_{i}} Y F A M_{i}\right)+\beta_{2}\left(\sqrt{m_{i}} Y F A M_{i}^{2}\right)+\delta_{1}\left(\sqrt{m_{i}} P R_{i}\right) \\
& +\delta_{2}\left(\sqrt{m_{i}} A P_{i}\right)+\delta_{3}\left(\sqrt{m_{i}} S P_{i}\right)+\delta_{4}\left(\sqrt{m_{i}} M P_{i}\right)+\delta_{5}\left(\sqrt{m_{i}} D_{1 i}\right) \\
& +\delta_{6}\left(\sqrt{m_{i}} D_{2 i}\right)+\sqrt{m_{i}} \varepsilon_{i}
\end{aligned}
$$

Our results are shown in Table $2 .^{7}$ Overall, the results obtained from estimating equation (3) are highly satisfactory. When all explanatory variables are retained, the corrected functional fits range from between 68 percent for 1976 and 44 percent for 1986 , while the $\mathrm{F}$ statistics are without exception significant at the 1 percent level of confidence. We consider the functional fits to be statistically satisfactory given the use of cross-sectional data. As such they offer general evidence in support of the hypotheses developed above.

Useful insights are provided by the estimates of $\beta_{1}$ and $\beta_{2}$. In each of the years under consideration, the levels of sub-state development, as proxied by mean family income, have impacted on regional income inequality. The nature of this relationship is far from uniform. In 1976, no evidence is provided of a quadratic relationship between development and inequality, as the $t$ tests for $\beta_{2}$ indicate that this parameter is not significantly different from zero at either the 1 or 5 percent confidence levels. Re-estimating equation (3) after the deletion of $Y F A M_{i}^{2}$, however, indicates the existence of a positive linear relationship between development and inequality as $\beta 1$ is significant at the 5 percent level. Re-estimating the equation for 1976 also reveals that $Y F A M_{i}^{2}$ adds little to the explanatory power of our model, as the deletion of this variable does not appreciably reduce the functional fit. The estimates of $\beta 1$ and $\beta 2$ for 1981 and 1986 are highly interesting. In both years these parameters are significantly different from zero, in- 
TABLE 1

Gini Coefficients for Australian Statistical Divisions

\begin{tabular}{llll}
\hline Statistical Division & 1976 & 1981 & 1986 \\
\hline New South Wales & & & \\
& & & \\
Sydney & 0.361 & 0.408 & 0.375 \\
Hunter & 0.360 & 0.402 & 0.356 \\
lllawarra & 0.338 & 0.384 & 0.353 \\
Richmond-Tweed & 0.384 & 0.402 & 0.345 \\
Mid-North Coast & 0.372 & 0.395 & 0.341 \\
Northern & 0.384 & 0.414 & 0.369 \\
North Western & 0.384 & 0.423 & 0.379 \\
Central West & 0.368 & 0.404 & 0.361 \\
South Eastern & 0.364 & 0.402 & 0.364 \\
Murrumbidgee & 0.364 & 0.406 & 0.356 \\
Murray & 0.369 & 0.403 & 0.356 \\
Far Westem & 0.366 & 0.406 & 0.359
\end{tabular}

Victoria

Melbourne
Barwon
South Western
Central Highlands
Wimmera
Northern Mallee
Loddon-Campaspe
Goulburn
North Eastern
East Central
Central Gippsland
East Gippsland

$\begin{array}{lll}0.352 & 0.390 & 0.357 \\ 0.361 & 0.384 & 0.342 \\ 0.378 & 0.404 & 0.348 \\ 0.368 & 0.397 & 0.353 \\ 0.370 & 0.425 & 0.358 \\ 0.385 & 0.414 & 0.356 \\ 0.383 & 0.404 & 0.348 \\ 0.374 & 0.397 & 0.344 \\ 0.368 & 0.377 & 0.329 \\ 0.375 & 0.385 & 0.331 \\ 0.362 & 0.382 & 0.347 \\ 0.372 & 0.425 & 0.358\end{array}$

\section{Queensland}

Brisbane
Moreton
Wide Bay-Bumett
Darling Downs
South West
Fitzroy
Central West
Mackay
Northern
Far North
North Westem

$\begin{array}{lll}0.356 & 0.386 & 0.341 \\ 0.381 & 0.408 & 0.355 \\ 0.391 & 0.410 & 0.350 \\ 0.387 & 0.410 & 0.355 \\ 0.401 & 0.439 & 0.386 \\ 0.372 & 0.404 & 0.351 \\ 0.406 & 0.436 & 0.390 \\ 0.405 & 0.447 & 0.371 \\ 0.366 & 0.392 & 0.341 \\ 0.387 & 0.418 & 0.367 \\ 0.340 & 0.396 & 0.349\end{array}$


TABLE 1 (Continued)

\begin{tabular}{llll}
\hline \hline Statistical Division & 1976 & 1981 & 1986 \\
\hline South Australia & & & \\
& & & \\
Adelaide & 0.343 & 0.384 & 0.349 \\
Outer Adelaide & 0.364 & 0.389 & 0.348 \\
York \& Lower North & 0.383 & 0.417 & 0.356 \\
Murray Lands & 0.348 & 0.391 & 0.358 \\
South East & 0.338 & 0.377 & 0.351 \\
Eyre & 0.365 & 0.405 & 0.379 \\
Northern & 0.328 & 0.376 & 0.340
\end{tabular}

\section{Western Australia}

Perth

South West

Lower Great Southern

Upper Great Southem

Midlands

South East

Central

Pilbara

Kimberley
0.346

0.354

0.367

0.415

0.441

0.349

0.367

0.320

0.380
0.388

0.389

0.428

0.453

0.429

0.404

0.417

0.396

0.452
0.354

0.352

0.370

0.397

0.386

0.365

0.369

0.331

0.380

\section{Tasmania}

Hobart
Southern
Northern
Mersey Lyell
0.361

0.362

0.357

0.352
0.395

0.396

0.387

0.385
0.344

0.340

0.340

0.334

Source: Maxwell and Hale (1988b).

dicating a quadratic relationship between the level of development, as proxied by mean family income, and income inequality. However, for $1981 \beta 1$ is positive and $b 2$ negative, while for 1986 the reverse is the case.

We interpret these results to be entirely consistent with our above-outlined contention that, in developed countries, the relationship between income inequality and development is one of minor oscillations around some longer-term trend. With respect to the estimates of $\beta_{1}$ and $\beta_{2}$ for 1981 and 1986, it would seem unlikely in the extreme that the relationship between income inequality and the level of development in Australian sub-state regions would exhibit an augmented inverted U-shaped pattern of the nature described by Amos, and then, 
TABLE 2

Regression Results

\begin{tabular}{|c|c|c|c|c|c|}
\hline \multirow[b]{2}{*}{ Constant } & \multirow[b]{2}{*}{$(\alpha)$} & \multicolumn{2}{|c|}{1976} & \multirow{2}{*}{$\frac{1981}{-0.07}$} & \multirow{2}{*}{$\frac{1986}{0_{0.54}^{* *}}$} \\
\hline & & $\begin{array}{c}0.23^{* *} \\
(2.89)\end{array}$ & $\begin{array}{c}0.12^{*} \\
(2.30)\end{array}$ & & \\
\hline YFAM $_{i}$ & $\left(\beta_{1}\right)$ & $\begin{array}{l}-0.2 e^{-4} \\
(-1.51)\end{array}$ & $\begin{array}{l}0.4 e^{-5 *} \\
(1.89)\end{array}$ & $\begin{array}{l}0.2 e^{-4 * *} \\
(3.35)\end{array}$ & $\begin{array}{l}-0.2 e^{-4 * *} \\
(-2.76)\end{array}$ \\
\hline$Y F A M_{i}^{2}$ & $\left(\beta_{2}\right)$ & $\begin{array}{l}0.1 e^{-8} \\
(1.83)\end{array}$ & - & $\begin{array}{l}-0.4 e^{-9 *} \\
(-2.17)\end{array}$ & $\begin{array}{l}0.3 e^{-9 * *} \\
(3.09)\end{array}$ \\
\hline$P R_{i}$ & $\left(\delta_{1}\right)$ & $\begin{array}{l}0.002^{* *} \\
(2.68)\end{array}$ & $\begin{array}{l}0.002^{* *} \\
(2.79)\end{array}$ & $\begin{array}{c}0.002^{*} \\
(1.95)\end{array}$ & $\begin{array}{l}-0.2 e^{-3} \\
(-0.18)\end{array}$ \\
\hline$A P_{i}$ & $\left(\delta_{2}\right)$ & $\begin{array}{c}0.01 \\
(6.44)\end{array}$ & $\begin{array}{c}0.01 \\
(6.29)\end{array}$ & $\begin{array}{c}0.01 \\
(5.82)\end{array}$ & $\begin{array}{l}0.001 \\
(0.89)\end{array}$ \\
\hline$S P_{i}$ & $\left(\delta_{3}\right)$ & $\begin{array}{c}0.01^{* *} \\
(3.36)\end{array}$ & ${ }^{0.01}{ }^{* *}$ & $\begin{array}{c}0.01 \\
(5.00)\end{array}$ & $\begin{array}{l}0.002 \\
(0.83)\end{array}$ \\
\hline$M P_{i}$ & $\left(\delta_{4}\right)$ & $\begin{array}{c}-0.011^{* *} \\
(-4.31)\end{array}$ & $\begin{array}{c}-0.01^{* *} \\
(-4.44)\end{array}$ & $\begin{array}{c}-0.011^{* *} \\
(-4.83)\end{array}$ & $\begin{array}{r}0.001 \\
(0.69)\end{array}$ \\
\hline$D_{1 i}$ & $\left(\delta_{5}\right)$ & $\begin{array}{l}0.02^{* *} \\
(3.52)\end{array}$ & $\begin{array}{c}0.02^{* *} \\
(3.85)\end{array}$ & $\begin{array}{c}0.01^{* *} \\
(2.39)\end{array}$ & $\begin{array}{c}0.01 \\
(1.82)\end{array}$ \\
\hline$D_{2 i}$ & $\left(\delta_{6}\right)$ & $\begin{array}{c}0.01 \\
(1.93)\end{array}$ & $\begin{array}{c}0.01^{*} \\
(1.91)\end{array}$ & $\begin{array}{l}0.011^{* *} \\
(2.33)\end{array}$ & $\begin{array}{c}0.02^{* *} \\
(3.51)\end{array}$ \\
\hline $\mathrm{R}^{2}$ & & 0.73 & 0.71 & 0.66 & 0.53 \\
\hline$\overline{\mathbf{R}}^{2}$ & & 0.68 & 0.66 & 0.60 & 0.44 \\
\hline F & & $15.21^{* *}$ & $16.01^{* *}$ & $11.15^{* *}$ & $6.40^{* *}$ \\
\hline$n$ & & 55 & 55 & 55 & 55 \\
\hline Method & & WLS & WLS & WLS & WLS \\
\hline Weight & & $\sqrt{m_{i}}$ & $\sqrt{m_{i}}$ & $\sqrt{m_{i}}$ & $\sqrt{m_{i}}$ \\
\hline
\end{tabular}

Numerals reported in parentheses are $t$ ratios.

** Significant at the 1 percent level.

* Significant at the 5 percent level. 
within a period of five years, come to exhibit a U-shaped pattern. ${ }^{8}$ With respect to Figure 2 above, it would seem much more plausible that during 1976, Australian sub-state regions were distributed between, say, points $b$ and $e$, while in 1981 they were distributed around a curve approximating that running through points $b, e$, and $f$, and in 1986 distributed along a curve running through points $e, f$, and $g$. These conclusions are supported by calculations of the values of $Y F A M_{i}$, which have been obtained from our estimates of equation (2) from Table 2. The rounded dollar values for 1976, 1981, and 1986, respectively, are 10,000,25,000, and 33,000. The 1976 and 1986 values are minima, while that for 1981 is a maximum. Given that the value for 1981 lies between those for 1976 and 1986, additional evidence in support of an oscillating pattern is provided.

Our estimates of the $\delta_{\mathrm{k}}$ parameters indicate that labor market, demographic, and geographic variables generally play an important role in determining levels of income inequality across Australian sub-state regions. Our estimates of $\delta_{1}$ suggest that sub-state participation rates $\left(P R_{i}\right)$ have positively impacted upon inequality in all years except 1986. With respect to 1976, this conclusion is drawn irrespective of whether or not $Y F A M_{i}^{2}$ is retained in our model. We draw the same conclusion concerning the aged population ( $A P i)$ and single-parent family ( $S P i)$ variables as both $\delta_{2}$ and $\delta_{3}$ are significant and positive in 1976 and 1981. In 1976 and 1981, $\delta_{4}$ is significantly different from zero at the 1 percent level and displays a negative sign; thus, supportive evidence is provided for our hypothesis concerning the importance of the recently arrived migrant variable $M P i$. Specifically, such migration seems to have reduced income inequality levels. However, given the insignificance of $\delta_{4}$ in 1986, it seems that the recent migration has also not impacted on Australian sub-state income inequality in this year. Finally, as both $\delta_{5}$ and $\delta_{6}$ are significantly different from zero in each year under consideration at either the 1 or 5 percent confidence levels, we conclude that remoteness and rural-urban differences, as respectively proxied by $D_{1 i}$ and $D_{2 i}$, seem to have positively influenced income inequality levels.

\section{CONCLUSION}

The purpose of this study has been to explain cross-sectional patterns of substate income inequality in Australia. In the study, particular attention was given to the relationship between income inequality and economic development. After employing multiple correlation and regression analysis, we observed relationships between Australian regional development, as proxied by mean family income, and income inequality. For the census years 1976, a positive linear relationship was 
observed, whereas for the census year 1981, a quadratic increase-decrease relationship was observed, and in 1986, a decrease-increase relationship was observed. We judge these to be consistent with our supposition that in developed nations, regional income inequality and development levels are likely to exhibit a pattern of minor fluctuations or oscillations around a longer-term trend, rather than the recurrence of a Kuznets cycle (i.e., Amos' augmented inverted U). Our analysis also indicates that a number of other variables have also impacted on Australian regional income inequality. These variables include the proportion of aged population, single-parent families, and recently arrived migrants, together with proxies for remoteness and rural-urban biases.

Finally, let us return to the inequality-development nexus and in particular the augmented inverted U hypothesis. As indicated in this paper, this hypothesis predicts that regions in highly developed countries will experience higher levels of inequality as development progresses. This pattern may imply that regional levels of income inequality would be reduced and stabilized if regional growth rates were equalized and relative regional mean incomes were held constant. Therefore, the impression may be given that a trade-off exists between higher levels of development and higher levels of inequality. Our results suggest that such a trade-off may not exist, so that well-intentioned government policies aimed at reducing differences in regional distribution of incomes (via attempts to equalize regional economic growth rates) may run the risk of impeding the overall growth rate of development without affecting the level of regional income inequality.

\section{ENDNOTES}

1. Maxwell and Hale (1988a), in adopting the Amos hypothesis, also fitted a similar equation to 1986 Australian cross-sectional sub-state data.

2. It should be noted that these contentions remain a matter of debate in the literature.

3. A number of earlier studies at both national and sub-national levels have also pointed to this. These include Maxwell and Peter (1988), Al-Sammarie and Miller (1967), Podder (1972), Murray (1978) and Bonnell, Dixon and Meagher (1984).

4. As a referee noted on an earlier draft of this paper, uni-directional causality between the additional regressors provided in equation (2) and regional income inequality may hold only in the short run. In the long run, it is reasonable to expect, a priori, that causality is bi-directional. 
5. For the 1976 and 1981 censuses, incomes of dependent children aged 15 to 20 were excluded from family income. Despite the perceived smallness of these incomes, the ABS's inclusion of them in 1986 family incomes reflects their growing and relatively uniform importance to Australian statistical divisions. Given the uniform importance of dependent children incomes, we are of the view that irrespective of size, their inclusion in 1986 does not invalidate comparison of econometric results based on data for 1976 and 1981 to those based on 1986 data, as made in Section $\mathrm{V}$ of our paper.

6. These divisions are excluded from our analysis on the grounds that the delineation of their boundaries reflects administrative convenience rather than demographic and economic criteria, as is the case with the remaining divisions. For further information on the delineation of Australian statistical divisions, see Department of Urban and Regional Development (1983).

7. Tests for multicollinearity among equation (3)'s explanatory variables revealed that while its extent was occasionally high, it was not of a magnitude requiring corrective measures. In addition, a number of alternative specifications of our model were estimated, including log-linear and semi-log-linear. The model was also supplemented by a number of additional variables, primarily dummies representing structural characteristics of sub-state regions under consideration. In each case, the results obtained were inferior to those reported in Table 2. Equation (3) can, therefore, be viewed as our preferred equation.

8. Maxwell and Hale (1988a) found no such evidence of a quadratic relationship. They did, however, use an altemative proxy for development level (each region's working-age population with post-secondary educational qualifications as a percentage of its total population) and used the ordinary least-squares, rather than the weighted least-squares, method of estimation.

\section{REFERENCES}

ABS. Census of Housing and Population. Canberra: Australian Government Publishing Service, 1976, 1981, and 1986.

Alonso, W. "Urban and Regional Imbalances in Economic Development." Economic Development and Cultural Change 17 (1968): 1-14.

Al-Sammarie, A., and H.P. Miller. "State Differentials in Income Concentration." American Economic Review 57 (1967): 59-71.

Amos, O.M. "Substate and SMSA Personal Income Inequality and Regional Development." Review of Regional Studies 16 (1986): 23-30. 
"Unbalanced Regional Growth and Regional Income Inequality in the Latter Stages of Development." Regional Science and Urban Economics (1988): 549-566.

Bonnell, S., P. Dixon, and G. Meagher. "A Description of Income Distribution in Australia: 1973/74 to 1981/82." Office of Economic Planning Advisory Council Discussion Paper. 85/04, 1984.

Department of Urban and Regional Development. Regions. Canberra: Australian Government Publishing Service, 1983.

Kuznets, S. "Economic Growth and Income Inequality." American Economic Review 45 (1955): 1-28.

- "Quantitative Aspects of the Growth of Nations: VIII. Distribution of Income by Size." Economic Development and Cultural Change 11 (1963): 1-80.

Maxwell, P., and M. Peter. "Income Inequality in Small Regions: A Study of Australian Statistical Divisions." Review of Regional Studies 18 (1988): 19-27.

Maxwell, P., and R. Hale. "Regional Income Inequality in Australia - What Does the 1986 Census Tell Us?" Curtin University of Technology Business School Working Paper. 2-88, 1988a.

"Trends in Regional Income Inequality - What Does the 1986 Census Tell Us?" Paper presented at the 12th Annual Conference, Regional Science Association, Australia. (1988b)

Murray, D. "Sources of Income Inequality in Australia." Economic Record (August 1978): 170-182.

Needleman, L. "On the Approximation of the Gini Coefficient of Concentration." Manchester School of Economics and Social Studies 46 (1978): 106-122.

Podder, N. "The Distribution of Household Income in Australia." Economic Record (June 1972): 181-200.

Williamson, J. "Regional Inequality and the Process of National Development: A Description of Patterns." Economic Development and Cultural Change 13 (1965): 3-84. 